\title{
9 Hostility on a T-Shirt
}

\section{Items with Language on Them}

In tourism, objects with 'language' on them are typically souvenirs, such as cups, decorative objects and T-shirts. Language on T-shirts appears to be particular. It poses a number of questions that emanate from where this language is placed and from where it originates. Is it the language of a place, or rather of a body? To whom does it speak, and of what? And who speaks? And does the T-shirt, this global garment, become local clothing through the words and images that are printed on it? Or doesn't this matter?

A T-shirt is not an easy item to study. It has its indexicalities that evolve out of its colour, material - recycled, eco-friendly or conventional cotton - and price. Not everybody wears it, making it a semiotic tool that signifies membership of a specific group or social sphere. In various contributions on youth culture, it has been addressed as part of style and stylizing practices shared by predominantly urban young people. Most notably, Roland Kiessling and Maarten Mous (2004) mentioned music, hair style and clothing as part of an entire performance of youth language, and this observation has since been repeated by many others. In a sociosemiotic study, Innocent Chiluwa and Esther Ajiboye (2016) suggested that the slogans and mottos printed on T-shirts deserve to be studied more intensively and detached from youth language research. In their work on the discursive pragmatics of T-shirt inscriptions, they treat the messages printed on garments as pragmatic acts through which - in this case 'Nigerian youths construct their environment and social aspirations' (Chiluwa \& Ajiboye, 2016: 436). T-shirt wearers, who in this case study are students, 'take some stances and discursively construct for themselves particular identities by which they position themselves and the Nigerian society they address', the authors observe. To them, 'a T-shirt demonstrates that fashion indeed can speak'.

Nicolas Coupland looks at T-shirt texts in a somewhat similar context: as landscaping in the 'sense of putting language on display in public arenas' in Wales (Coupland, 2010: 79). T-shirts with playfully altered Welsh catchwords on them are 'ironic, creative and deeply coded textual representations of cultural values and antagonisms' (Coupland, 2010: 96). 
These perspectives on language worn on the body are informed by the idea that language is fluid and local practice (Otsuji \& Pennycook, 2010), and that variation in language practice needs to be researched with a focus on stylistic issues rather than static concepts. Arguing with Penelope Eckert (2012), there is a strong tendency to understand such creative language practices and these forms of linguistic landscaping as ways of positioning oneself as a speaker, of stylizing one's social and communicative appearance and role. This ties in with new perspectives on language as a whole:

In the move from the first to the third wave of variation studies, the entire view of the relationship between language and society has been reversed. The emphasis on stylistic practice in the third wave places speakers not as passive and stable carriers of dialect, but as stylistic agents, tailoring linguistic styles in ongoing and lifelong projects of self-construction and differentiation. It has become clear that patterns of variation do not simply unfold from the speaker's structural position in a system of production, but that they are part of the active - stylistic - production of social differentiation. (Eckert, 2012: 97f.)

This might make a lot of sense when thinking about language on a Nigerian metropolitan campus, or in Northern settings such as Wales. But what about tourism contexts? Settings that are shaped by messy, conflicting and transgressive practices? At least in terms of items sold and profits made, these are the settings in which the language on T-shirts is really important. They matter for yet another reason, at least. They inscribe what is positioned, already scripted into our bodies, through the ways in which our presences come into existence, through the racialization of class and through the semioticization of the spaces into which we travel. If not for noisy prints and shouting slogans on our bellies, what would remain? Silence, we suppose. Because what can be worn there finds no addressee: the writing on the shirt is not directed at anybody on that beach; it means me/us. But how? And why do we buy and wear this?

\section{Three T-Shirts}

Three T-shirts were bought in souvenir shops that almost exclusively catered to European or Northern tourists who visited holiday destinations in the South: Cairo, Zanzibar and Mallorca. The T-shirts were produced there (where they were bought) for customers who were Northern tourists. The shirts were worn at the tourist destinations.

At first, we thought about gossip. A T-shirt is such a leisurely form of dress, so much connected with having fun and being sporty, etc. - this should be a message about the banality of daily life. Moreover, we had recently seen an East African leso with a print that was about gossip, so the connection was easily made. But then the T-shirt shown in Figure 9.1 was part of a collection that differed somewhat from the usual fare. The 


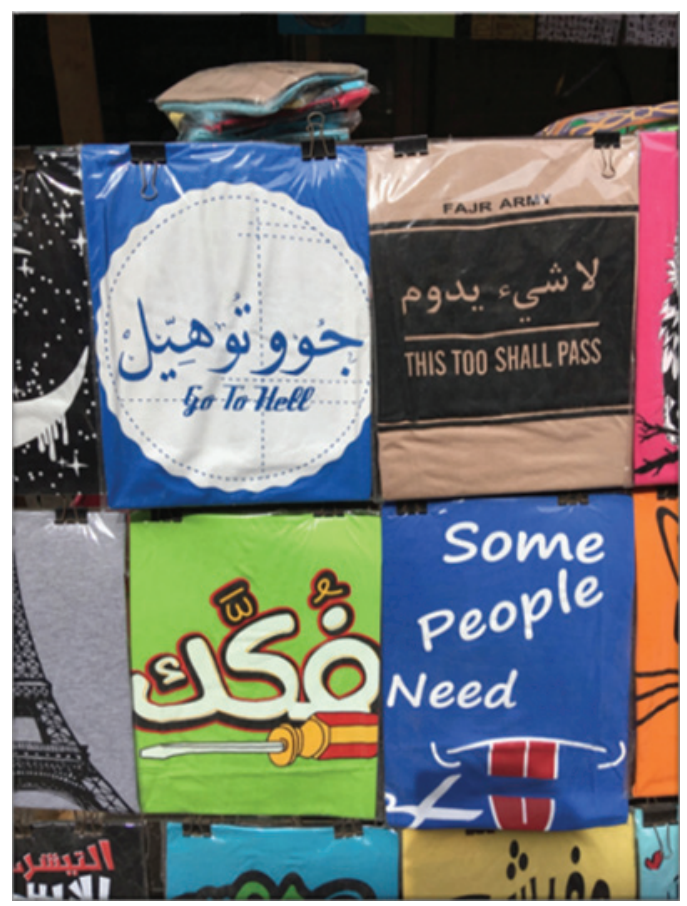

Figure 9.1 First T-shirt: Cairo

shop that offered these T-shirts also had little pyramids and other such objects, a large collection of T-shirts with prints that depicted the Simpsons as pharaonic Egyptians, and then this.

There was a very visible difference between the usual tourist fare and the designs on display here. On a separate table, shirts that did not easily make sense as stereotyped 'Egyptian' were shown: 'Go to hell' written with Arabic letters; 'This too shall pass' on a pirated Fajr Army shirt (Storch \& Warnke, 2020); and then this cut tongue: 'Some people need to have their tongue cut.' We were reminded of the failed revolution followed by the military coup in 2013. All over the market, with its colourful yet monotonous souvenirs, there were banners celebrating Abd al-Fattah asSisi, Egyptian president since 2014. For four years now, Egyptians had been dealing with increasingly tight control over what they said: by the secret service and the police, with the military everywhere in public spaces. The previous year, we had been to Giza in order to research the multilingual repertoires of tourist guides; we saw very few tourists, but there was a massive secret service presence. Everywhere there were men discreetly dressed in blue suits - sitting at the foot of the great pyramids, strolling along the road that leads to the Sphinx, standing beside the camels that were offered for a ride. The guides and souvenir vendors around were eager to talk to us, about language as well as about its 
absence - how it had become hard to find tourists to whom one could speak in German, Italian or even English, and how the state controlled and harmed Egyptian citizens. But every time one of these men in blue suits came closer, an entirely different discussion would be performed: talk about souvenirs, prices, tours. Tourist talk. Once the secret service were at a safe distance, the discussion would return to its original topics.

So perhaps the blue shirt with the red tongue on it was about censorship and military rule? About Egypt being a place where citizens had few civil rights? A proof of having visited one of these countries that are ruled by dictators, fundamentally different from Europe, an Oriental country? We wonder whether this T-shirt was made for people who look at the world like this.

Or perhaps there is a different kind of hidden meaning involved here: the T-shirt makers may have been making an ironic statement that is neither kind to the tourists who buy it nor to those it refers to.

The T-shirts in Figure 9.2 were sold in a souvenir emporium in Zanzibar's Stone Town, where people can choose from large amounts of similar things offered in many similar-looking shops. There is very little originality, nothing too outstanding, just recurrent themes of Hakuna Matata and Freddie Mercury, mostly produced in China. Yet tourists buy the T-shirts on offer and wear them during their holidays. A particular

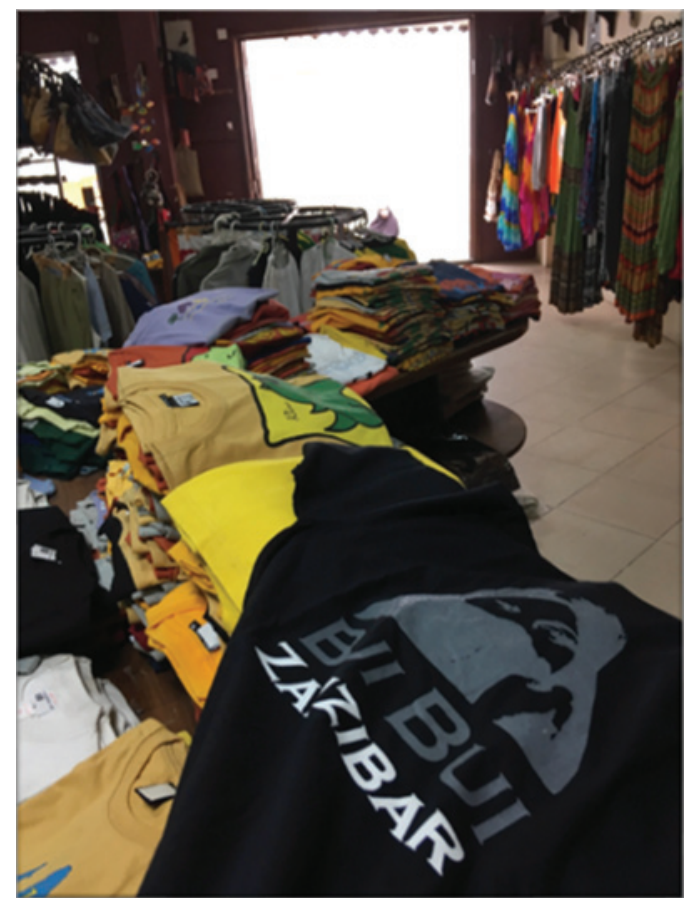

Figure 9.2 Second T-shirt: Zanzibar 
type of T-shirt stands out: one that is neither about the Land of Hakuna Matata nor that portrays humorous messages about life in Tanzania, but that has a very direct way of depicting what is exotic and Oriental in Zanzibar. The picture of a veiled woman is accompanied by the print BUI $B U I Z A N Z I B A R$, the Swahili word for the veil, and then the non-Swahili word for the island. The Other is a woman wearing a black veil. A buibui woman, a woman whose body is invisible, who walks these streets too, at the same time as the tourists, but whose presence refers, it seems, to a different time. Not yet liberated, not yet in hot pants. The tourists who look at this T-shirt are young, and most of the women we see wear very short pants and very short tops. They look inadequate to us, but their wearers do not seem to mind. We think of The Burka Avenger, a popular Pakistani cartoon, and whether we can make a connection. The buibui woman will not fight for anybody's rights, we assume, but will hover above some unclad legs and very short pants. Look at this Oriental relic, the print seems to say, she still exists, and like the image of a rhino or hippo or shark, one can wear her as a kind of testimony of that particular encounter: with authenticity and the past. There is no superhero depicted on the T-shirt, but a symbol of Orientalism and allochrony (Fabian, 1983; Said, 1978, etc.). And yet ... the buibui woman makes a powerful statement. She may be appropriated in an almost unbearable way, but she makes it painfully clear that tourism on Zanzibar is utterly neocolonial, transforming most of the former plantation economy into a tourism economy, tourism already being the island's largest economic sector. Much of this tourism is not in any way interested in the communities on the island and instead is embedded in the global economy, which leaves little and takes much. More recently, communities of the much-visited northern coastal region of Zanzibar have protested against the unwanted effects of tourism, such as drug trafficking, public sex work and improper conduct by the visitors.

This T-shirt, we think, refers to alienation and various forms of violence, which are situated in settings of multitemporality: that what is over is not over. The colonial economies of exploitation are felt, and they have their effects in how we can consume or reject the bodies of Others. And there is reason to believe that the Others know what is happening. More recently, the Zanzibari fashion designer Doreen Mashika has marketed a collection of T-shirts and printed phone cases that bear photographs of Zanzibari people - rural women, Maasai beach workers - who did not seem to welcome those who were staring at them. There was humour in this, too, but also a story about the perfectly audible voices of Others.

At El Arenal, a party tourism destination on the Mediterranean island of Mallorca, the voice of the Other is part of it all: the beach and streets leading to the party locations are not only places where tourists perform transgressions and express their desires for rupture, but also where a very performative encounter with those who provide the party space with the 
necessary commodities takes place. West African beach vendors, Chinese masseurs, Spanish and Romanian vendors of Romani descent who sell drinks and fruit, and others walk up and down these areas and offer their goods to the - mostly German - tourists. Often, vending involves a certain type of masquerade, for example by Senegalese selling sunglasses, who wear costumes and play with giving names to others and being named. Helmut is one of the most frequently used names for both the vendors and their male customers. Female customers are often referred to as Lady Gaga, but also as Monika, Gisela, and so on. Other players participate by mocking or mimicking the Other, such as Nigerian sex workers who address their German clients by simply offering the ficki ficki, blasi blasi 'fuck fuck, blow job blow job', and who are in return, mimicked and mocked in the same way by the Germans: ficki ficki, blasi blasi.

The T-shirt shown in Figure 9.3, with the printed rejection of all this, has been around for several years now. Its popularity among tourists seems to have increased rapidly with the success of a party hit that was based on an objectification of the Helmut persona as an undocumented Senegalese migrant who is yet somehow cool: Senegal, illegal, doesn't matter.

Now, the T-shirt has been offered in a kind of upgraded version: there is not only the rejecting text on the front, but also - headed by the toponym Mallorca in Gothic font - no in large letters three times, in combination

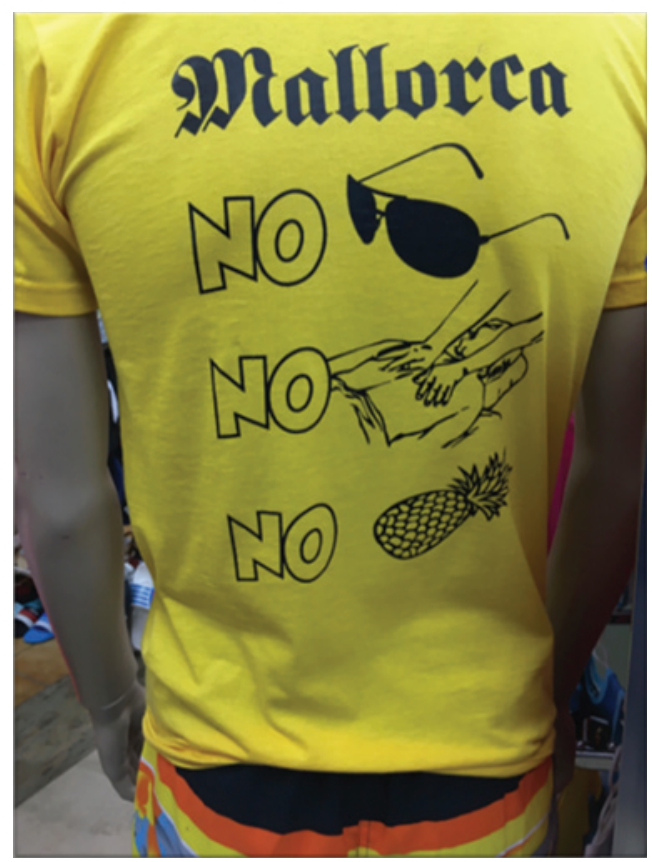

Figure 9.3 Third T-shirt: Mallorca 
with signs that refer to the emblematic businesses of the presumably undocumented migrant workers at the beach. You might not be able to read, but you will understand this, the T-shirt signals. And Mallorca is ours, not yours, so you'd better go. Those who wear these shirts still engage in playful conversations with those whose rejection they embody.

The shops along the playa where these T-shirts are sold are almost all run by Indian families. They select motifs to be printed on the T-shirts from a catalogue of a designer and merchant based in Barcelona. About 2000 motifs are available. The range from which the tourists can select a motif contains several dozens of prints, and besides the T-shirt seen here, there are some ten more that seem to be constantly wanted. Most of them are misogynistic, othering and hostile. All of them are considered funny and relevant for inclusion in the party crowd.

The messages printed on these T-shirts that are marketed as tourist commodities are hostile and are part of rejecting speech acts directed at the hosts of the people who might wear these garments. There is a recurrent strategy to construct the host as the Other, as a commodity, Oriental, strange, foreign. Yet those who wear these prints usually do not design them or produce these T-shirts (even though in Mallorca tourists actually do design their own shirts, but these are usually worn only among small groups for special occasions, such as stag parties). They need complicity in making the Other, which we assume are the stakeholders in local as well as global souvenir industries. But they also are complicit: tourists actually wear these T-shirts, at the holiday destination and maybe elsewhere too. There is a strange form of incorporation of this rejected Other going on here: wearing this other skin, sailing under a false sail. The wearer seems to be a friend, one who at least takes notice of the marginalized players around him or her, but then this might turn out differently. The materiality of language (and the language of materiality) as it exists in the context of late capitalist mobilities is a salient part of the global tourism industry, where it is turned onto itself in almost metaphysical ways. These materializations of the Self and Other seem to transgress the boundaries of body as well as place, which makes them semiotically complex and ambiguous. There is no single reading of these transmodal motifs and signs that express privilege and marginalization, closeness and alienation, rejection and complicity at the same time, and that depend on positionality and context to unfold their performative logics of difference. To wear the Other right on your body, to print the Other's name and face and tongue on whatever offers the space for it, what hostility this is!

\section{Language Course}

The particular ways in which these T-shirts exhibit language as something specifically connected to a place - for example to the challenges it might pose to its visitors, or to the Otherness the inhabitants of a place 
represent, or to its celebratedness as a globalized emblematic party space tend to be understood as a form of language commodification, by turning language into an object and exchange value. The words on the T-shirts do not indicate what they might indicate in other contexts, for example referring to objects and events in which these objects play a role, or to the emotional responses specific encounters may elicit; instead they indicate the meaning of language as something that is immediately and unequivocally connected to economic profit. Language as commodity would be language on a T-shirt, someone's multilingual capacity used as an objective skill (for example of a tourist guide), or a marketed slogan in advertisements, and so on. Monica Heller's work (Heller, 2011, among others) has been crucial in introducing the notion of the commodification of language in late capitalism into contemporary sociolinguistics, and has encouraged numerous contributions on the objectification of emblematic slogans and on speakers' performances and choices, as well as on written language in urban environments (in the sense of linguistic landscapes). Even though many of these contributions have helped to raise awareness among linguists of the fact that language is greatly affected by the extractive and exploitative neocolonial world order in which we live, the debate on the commodification of language - and the term 'commodification' itself - have strangely remained uninterested in a deeper understanding of the ways in which language itself changes through these processes.

In his work on Social Class in Applied Linguistics, David Block (2014) problematizes this situation. He argues that the term 'commodity' itself needs to be read in the light of Marxist theory, from where it originally stems, even though many of those sociolinguists who use the term today (including Heller herself) often do not explicitly refer to this context. Block explains further that

In Marx's work [...], a commodity is a product of human labour. It has value, initially and at the most basic level, for the uses that can be made of it. This value is reflected in how, for example, linen can be used as sheets on a bed, shoes can be used to protect one's feet, a fork is used to eat with and so on. All such objects mediate the satisfaction of basic biological and ideational needs and wants. From commodity production for such basic qualitative value, there is a shift as markets (and market-based economies) arise as sites from which individuals can acquire that which they need or want but which they cannot or simply do not produce themselves. In markets, commodities have exchange value, which means that they can be exchanged for other commodities, as would be the case in a barter economy. Crucially, with market exchange, there is the beginning of a separation between the social relationship of the individual in the production of a commodity and the act of its exchange. The acquirer of a commodity only comes into contact with the finished product but not the socially necessary labour expended by the person who produced it. This is the beginning of a disconnect between the social relationship of production processes and end products. (Block, 2014: 136) 
Keeping Marx's interpretation of what is a commodity in mind, Block argues, the idea that language might be commodified becomes questionable. First of all, he observes, a commodity in Marx's sense is always the product of human labour. And language, in all the different ways in which it is acquired, shared and transferred, is hardly the product of human labour. Furthermore, Block observes that, unlike a commodity, language does not owe its usefulness to itself; it never simply serves as an article of something else (such as 'wheat [...] serves as an article of food', Marx, 1904: 34-55, cited in Block, 2014: 137). It has no cost of production that defines its market value, and even an instance of language - such as a proverb or a slogan like Hakuna Matata - cannot be measured in value as we cannot, by any means, estimate the costs involved in its production. It is different when we consider the copyright given to individual authors whose text production is in some way measurable and where the product of someone's labour can be valued and marketed. Therefore, T-shirt prints such as BUI BUI ZANZIBAR might serve as illustrations of the work of individual designers, whose products are commodities sold at the global tourist market, but who do not commodify Swahili as such.

One could argue, in line with Heller (2011) and others, that the marketing of language skills in the framework of language schools and in the classroom does indeed turn language into a value, costing the amount that one must pay for an evening class, for example. And language courses do indeed serve as indicators for the value a particular language skill might have on the job market. A rising interest in Chinese in many parts of Africa is reflected by an increase in the numbers of Chinese language courses at universities, private language schools and on online forums. But the value of Chinese is not the value of the language itself, but of the labour provided by the administration and teaching staff of those institutions, the materials produced by authors of language course books, the costs involved in printing and photocopying. Turning the gaze to the tourist market once more and the ways in which language courses and learning are represented by the souvenir industry, Block's point might become even more obvious. Souvenir shops in Kenya and Tanzania sell large varieties of T-shirts with language course materials printed on them. As a genre of its own, the language course T-shirt might insinuate even more than other T-shirts, such as those presented above, the commodification of language. The linguistic material on them is usually combined with drawings of the objects denoted by the words in the language in question, and everything is arranged in a symmetrical, orderly way on the front of the garment, as if the systematic process and normative practice of the language course is to be embodied by the wearer.

An example is a child's T-shirt purchased in Diani, Kenya. Made of eco-friendly cotton (according to the label), the object has been advertised as "cool wear "original designs *Africa made. The T-shirt is of an olivebrownish colour that evokes memories of safari advertisement designs. 
While the back is devoid of any print, the front bears a print that extends from just under the neckline down to the bottom seam. On top, in multicoloured capital letters written in a 'playful' font, it says KISWAHILI FOR YOU. Underneath, we are provided with a vocabulary':

(1)

JAMBO
RAFIKI
NZURI
ASANTE
WANYAMA
SIJUI
HAKUNA MATATA
CHAKULA
KWAHERI

$$
\begin{array}{ll}
- & \text { HI } \\
- & \text { FRIEND } \\
- & \text { GOOD } \\
- & \text { THANK YOU } \\
- & \text { ANIMALS } \\
- & \text { I DON'T KNOW } \\
- & \text { NO PROBLEM } \\
- & \text { FOOD } \\
- & \text { GOOD BYE }
\end{array}
$$

To the left and right of the wordlist are drawings of a Maasai warrior, a lion, a chicken leg, a sun, a hand waving and so on. A small colourful braid that imitates African prints on kangas can be seen underneath.

A T-shirt in an adult size was bought in the same tourist environment in Kenya and resembles the first T-shirt in terms of its olive colour, again suggesting safari contexts. The print is arranged in a similar way, with a heading underneath the neckline, vocabulary on the belly, images of objects to left and right, and a decorative 'African' element underneath. The vocabulary offered by the T-shirt is much more elaborate and not just written in capital letters. Moreover, the images are included in the language course more explicitly. The heading is bilingual - LEARN SWAHILI Jifunze Kiswabili. Underneath we read:

$\begin{array}{ll}\text { (2) Hello } & \text { Jambo } \\ \text { How are you? } & \text { Habari gani? } \\ \text { Fine } & \text { Mzuri sana } \\ \text { Welcome } & \text { Karibu } \\ \text { Goodbye } & \text { Kwaheri } \\ \text { Thank you } & \text { Asante } \\ \text { No problem } & \text { Hakuna matata } \\ \text { Friend } & \text { Rafiki } \\ \text { Enough } & \text { Inatosha } \\ \text { Shop } & \text { Duka } \\ \text { Market } & \text { Soko } \\ \text { Food } & \text { Chakula } \\ \text { Tea } & \text { Chai } \\ \text { Spoon } & \text { Kijiko } \\ \text { Coffee } & \text { Kahawa } \\ \text { Beer } & \text { Pombe } \\ \text { How much money? } & \text { Bei gani? } \\ \text { Slowly } & \text { Polepole } \\ \text { Small } & \text { Kidogo } \\ \text { Big } & \text { Kubwa } \\ \text { Please } & \text { Tafadhali }\end{array}$


Underneath, khaki-coloured letters say WELCOME KARIBU, and to the left there are drawings of animals with explanations underneath each of them: Lion-Simba, Zebra-Punda Milia, Elephant-Ndovu, CheetahDuma. To the right there are Leopard - Chui, Giraffe - Twiga, BuffaloNyati, Hippo - Kiboko.

A third T-shirt of this type was bought in a tourist emporium in Stone Town in Zanzibar. It is a thin white shirt without sleeves, with no print on the back and a symmetrically arranged vocabulary on the front. The heading reads ZANZIBAR LEARN SWAHILI, and underneath an extensive vocabulary is offered:

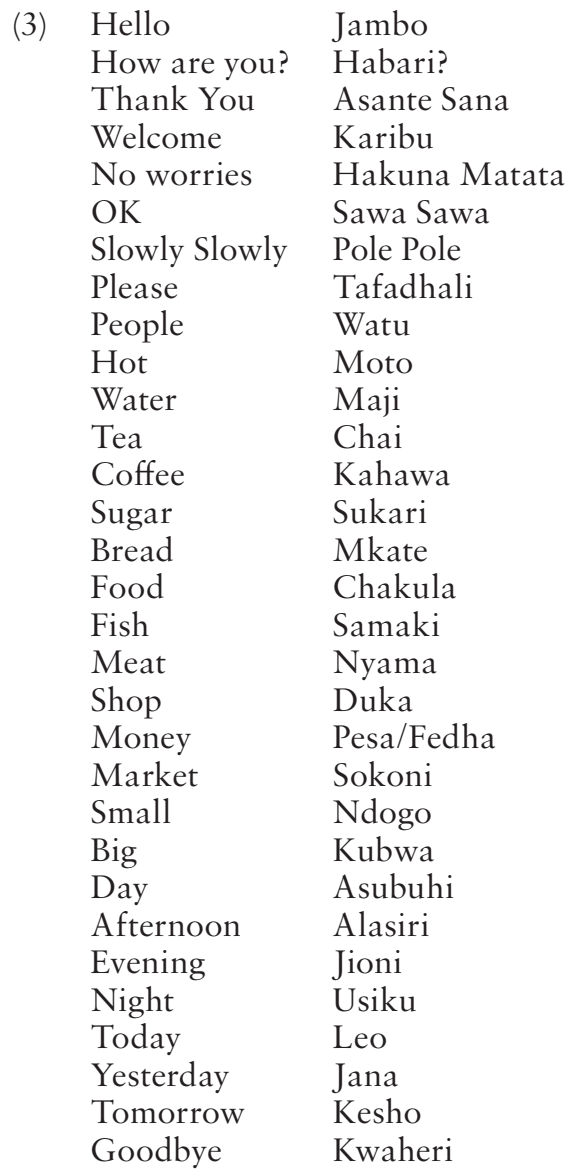

To the left, images of animals are labelled as Rhinoceros ... Faru, Cheetah ... Chui, Elephant ... Tembo, Ostrich ... Mbuni, Hippopotamus ... kiboko, and to the right as Lion ... Simba, Zebra ... Pundamilia, Giraffe 
... Twiga, Impala ... Swala, Buffalo ... Nyati. There is no decorative element underneath the vocabulary.

Similar motifs are offered as prints on other objects that can be used in everyday routines. A placemat made of laminated cardboard has a zebra stripe design and images of zebras as a background, on which the heading I Kenya LEARN SWAHILI has been printed. Below, there is a wordlist that is remarkable insofar as to some extent it attempts to makes sense of the connection of the object with the meal:

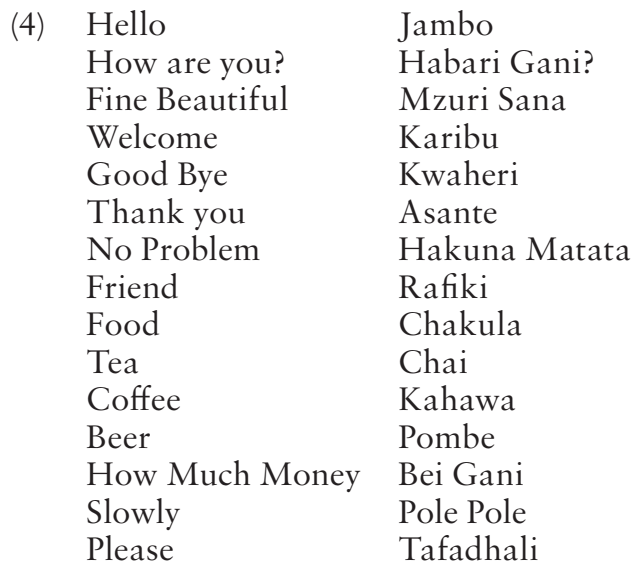

To the left and right of the wordlist, there are images of animals and maps of Africa and Kenya.

A wall hanger and a fridge magnet, also bought in Kenya (Diani), offer similar language material. The wordlist is printed on a space that resembles an ancient scroll and reads:

\begin{tabular}{|c|c|c|}
\hline Jambo & - & Hello \\
\hline Kwaheri & . & Goodbye \\
\hline Hakuna & - & No \\
\hline Matata & - & Problem \\
\hline Asante & . & Thank you \\
\hline Karibu & - & Welcome \\
\hline Pombe & - & Beer \\
\hline
\end{tabular}

On top of it, the heading says LEARN SWAHILI, and underneath KENYA has been printed on the scroll. To left and right a Maasai woman and a Moran can be seen.

A coffee mug from Kenya (Diani) asks us to Jifunze Kiswabili-Learn Swahili and bears vocabulary and illustrations of the words to be learned, arranged in a slightly messy fashion. The vocabulary is thematically less 
consistent, as if the designer wanted to make reference to the ways in which chats over a cup of coffee meander from here to there:

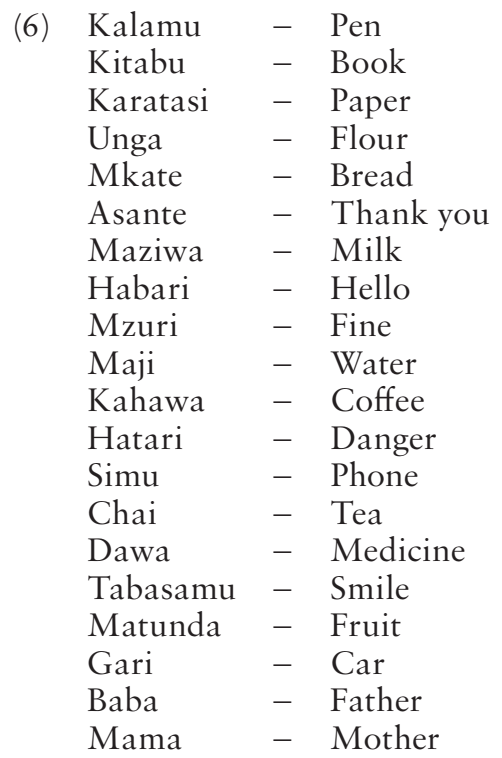

What is being marketed as a commodity here are objects that have been produced by local designers or Chinese (or other foreign) companies. The language printed on these objects always consists of more or less the same words and phrases, and it is always Swahili. As in the context of Hakuna Matata, Swahili is taken here to represent Kenya, Tanzania, Zanzibar, Africa. Never do any words in Maa or Gikuyu or any other language spoken at the sites of tourism appear on these objects - Swahili vocabularies and slogans adorn these things in the same ways as the images of animals seen on safari trips do, or the decoration and colour associated with 'African' aesthetics does. All this is not really 'Swahili', as a language or a practice, but an extremely reduced and emblematically framed representation of what a tourist might, after a short holiday, consider to be an 'African language'. The words taught to tourists by guides and souvenir vendors reappear on these objects and remind us that the tourism industry involves different forms of labour. The transfer of emblematic vocabulary in order to make the safari or guided tour more interesting and local, in the sense of more 'African', is part of the work that is done. But this work does not consist of the production of the language itself, nor do the designers of souvenirs produce Swahili; they produce representations of an experience of a Swahili-speaking tourist site.

These reduced and simplified representations of Swahili have their earlier counterparts. As observed by Judith Irvine (2008), among others, the beginnings of African linguistics are characterized by representations 
of African languages as languages that lack any complexity. Data on African languages, Irvine shows, were often collected and produced with the help of people who had left their homes a long time ago, had been kidnapped and enslaved, or were met by the early missionary linguists in one of the many refugee camps that existed in various parts of the continent after the abolition of the slave trade. Irvine argues that there is a close connection between imperialism and the lacking representations of African languages well into the era of decolonization. The texts on which our knowledge of African languages is based are problematic to no small extent, and this should be carefully reflected on:

These conditions of linguistic work tended to result in representations of African languages in reduced versions, lacking in social deixis other than pronouns and kinship terms, and simplified in syntax. (Irvine, 2008: 331)

The decoration of souvenirs suggests that learning a language such as Swahili is still the appropriation of the reduced and simplified language of the Other, as if the Other was not able to express anything complex, as if the vocabulary on the T-shirt was just as good as the buibui-wearing woman from Zanzibar for representing the exotic and Oriental Otherness of the colonial place and its inhabitants.

Language printed onto a commodity undergoes two processes of alienation, it seems - the disconnection between the person who produces the commodity and the person who buys it in a market economy, and the disconnecting relationship between the (presumed) producer's way of speaking and the customer's estimation and interpretation of it. Power imbalances that are nothing more and nothing less than imperial debris suddenly become painfully discernible through the marketing of commodities to which the language and the image of the Other are attached. And even if these T-shirts and mugs were considered too banal to be looked at in any detail, the effects of the ruinous representations of Othered language remain discernible. As Cronopio (2019) argues, discourse on and at the sites of tourism - in this case backpacker tourism in Morocco - can be analysed as predominantly interested in the expression of egocentric perspectives, where the people who inhabit the places visited by the travellers are reduced to decoration and accessories that provide some sense of authenticity. The travel books that are found in backpacker hostels, hotel rooms and libraries, as well as in the bags of the tourists themselves, provide similar insights. The reduction of a language to emblematic decoration pervades guides and travel books, where literacy pertaining to the Other very often constructs Orientalist images of stereotyped people who have no real language of their own, but only dialects and idioms. These figured Others need someone to give them a voice, it seems, a voice rather than words.

In James Penhaligon's (2011) Speak Swahili, Dammit!, an autobiographical text on the author's childhood in Tanzania from 1966 onwards, 
language is provided as snippets. These snippets are easy to identify as they are always printed in italics. They stage authenticity, give credibility, raise curiosity. This could have been said about many other books that are sold in the bookshops at airports and the travel book selection of online booksellers, but Penhaligon's book has such a good title that we have chosen his volume and not anybody else's. Open the book randomly. 'Fifteen', pages 169-188. The chapter's italic version reads as follows:

(want; English; emphasis)

Watu 'Samaki muzuri' 'Sitaki' Mzungu? 'Sitaki' 'Usi pigana' 'Nami kukimbia' 'Apana' 'Kwa nini?' totos watu askaris schutztruppe Afrika Korps Kriegsmarine askari KAR askari KAR Central African Rifles Kimbo

(that; English; emphasis)

KAR KAR askaris Schutztruppe KAR KAR watu KAR askari KAR Schutztruppe askaris askaris bibi Schutztruppe askari bibi Whitecap askaris rafikis 'kushoto, kulia, kushoto, kulia' Kushoto Kulia askari 'Hawa' kak-ak-ak-ak-a Plop-plop-plop askari Mzungu kunya askari askari nyokas ka-boom Mzungo ndogo askari Brrr-aa-a-ppp Anakufa kabisa banzaai banzaai 'Asante, ndugu ndogo' hakiri ugali mboga mboros jigi-jigi Two-Mboros Three-Mboros Four-Mboros Kwa kibiriti ya kupata matiti, katika Dodoma kupata kuma lakini kwa rungu kupata mkundu! Rungu novus actus interveniens mchawi mwamba watu ng'ombe mzee watu jinni djinn mchawi wasikini masikini masikini masikini 'Jambo' mwamba 'Nini Mzungu?' wasikini mchawi dawa 'Ku-ulisa' 'Aw-omba' hekima hekima 'Uta rudi'

(will; English; emphasis)

Mchawi masikini masikini

(in; English; emphasis)

Wazungu bibi jigi-jigi mutu jigi-jigi jigi-jigied bibi Whitecap kanzu fez Harley Davidson Whitecap Harley Davidson

(him; English; emphasis)

Mbuia Wazungus Whitecaps Wazungu bibi shamba Wazungu 'Morning Please Don't Come' Mzungu Whitecap shamba Timbuktu makuti maninga pièce de la résistance Club Timbuktu

(spirit; English; emphasis)

Club Timbuktu watu Wazungu SS Orion Orion Warabu Swahilis Chagga bibi kuja hapa, leta Watoto Mzungu 'Leta meno ya tembo' watu Timbuktu Mzungu Whitecap watu kabila Johnny Walker bibi bibi bibi.

The words do what they have to do, in this commodity-book. They put into the text what it needs in order to convey the weight of experience and lived-through reality. German words that are about war, Japanese words 
that are about the battle cries of the Kamikaze pilots, Swahili that is about witchcraft and obscenity, poverty and women. And then there are the different names for different people: Johnny Walker tribe. On the back cover of the book, recommendations can be found. The Executive Director of the KAMUSI PROJECT INTERNATIONAL, The Living Internet Swahili Dictionary, Switzerland writes: 'What a compelling window into a unique part of the Tanzanian experience ... a different world, illuminated from a fascinating perspective.'

Peter Moore's (2002a) No Shitting in the Toilet, a 'travel guide for when you've really lost it', offers autobiographical data as well, but from the perspective of a traveller. Swahili is explained where it is most saliently encountered by travellers, namely in emblematic soundscapes and foodways:

\section{TOP TEN TRAVELING TUNES}

4. 'Jambo Bwana': The Kenyan Safari Band

To me - and to anyone else who's heard of it - this song is Kenya. Contrary to popular opinion, it isn't the happy, carefree nature of this tune that endears it to folk. Nor is it the fact that it uses the only two Swahili phrases most people ever remember - jambo bwana and mzuri sana. No I'm afraid it's rather more perverse than that. It's because you hear the bloody thing so many times

(From This is the Kenyan Safari Band, produced by some crappy pirate tape outfit on Tom Mboya Street, Nairobi) (Moore, 2002a: 204)

Matoke

Mashed plantain bananas and maize. Second only to ugali as the most unpalatable meal on the planet. (Moore, 2002a: 253)

Ugali

A tasteless mixture of maize and water that leaves you feeling leaden and queasy. Unfortunately, it will be your staple diet in Africa. (Moore, 2002a: 256)

We know this trope. Ugali, like Swahili, represents Africa.

In Moore's book about his trip from Cape Town to Cairo, Swahili for the Broken-Hearted (2002b), this becomes even clearer as we browse through the chapters. Each of them, regardless of which experience, city or country it describes, begins with a Swahili proverb. All of these proverbs are translated into English, which makes this book a bit similar to the language course souvenir T-shirt. A selection of proverbs reads as follows:

Baada ya dhiki, faraja.

(Prologue)

After hardship comes relief.

Mwenda mbio hujikwaa dole.

(Cape Town, South Africa)

A person in too much of a hurry stubs his toe. 
Kila ndege huruka kwa bawa lake. (The Garden Route, South Africa) Every bird flies with its own wings.

Shoka lisilo mpini halichanji kuni. (Lesotho) An axe without a handle does not split firewood.

There are 21 chapters, one on each destination or stopover, each with a proverb of its own. The chapter on Zanzibar begins with Asiye na mengi, ana machache 'Even he who has not many troubles has a few'. Apart from the trans-African proverbs, there do not seem to be any Swahili words in the book, even in the Zanzibar chapter. Instead, the words printed in italics in this chapter refer to a Monty Python film and to classic English literature (Life of Brian, Wuthering Heights, Sons and Lovers, Tess of the d'Urbervilles, A Pair of Blue Eyes).

Novels for proverbs, Swahili words for English words, a barter trade of language on a market of desires and phantasies, where anything gets sold. The texts sold in the souvenir shops do what we might expect them to do, as they continue drawing images of an Other who has no Self, of destinations frozen in exoticism, of language that says nothing. Linguists, who produce much more complete and inclusive representations of language, usually do not see this as a problem. But what is actually becoming visible in this market of dreams is that the imperial formations that govern the ways in which language - or rather speech - is taken control of and made alien to the speakers remain firmly in place.

\section{Note}

(1) All examples are transcribed from the original objects, faithfully reproducing font and format. 


\section{Chapter 10}

MOVIES ON

SEX TOURISM

THAT YOU

SHOULDN'T

MISS 